\title{
Post-Great-Recession Human Migration Patterns in the U.S.: The Overlooked Impacts of Entrepreneurial Activity and Personal Freedom
}

Richard J. Cebula

George Mason University, Virginia, U.S.

Follow this and additional works at: https://digitalcommons.newhaven.edu/americanbusinessreview

Part of the Entrepreneurial and Small Business Operations Commons, and the Other Business Commons

\section{Recommended Citation}

Cebula, Richard J. (2021) "Post-Great-Recession Human Migration Patterns in the U.S.: The Overlooked Impacts of Entrepreneurial Activity and Personal Freedom," American Business Review. Vol. 24 : No. 2 , Article 7.

DOI: https://doi.org/10.37625/abr.24.2.133-146

Available at: https://digitalcommons.newhaven.edu/americanbusinessreview/vol24/iss2/7 
Post-Great-Recession Human Migration

Patterns in the U.S.: The Overlooked Impacts of Entrepreneurial Activity and Personal Freedom
American Business Review

Nov. 2021, Vol.24(2) $133-146$

(c) The Authors 2021, CC BY-NC

ISSN: 2689-8810 (Online)

ISSN: 0743-2348 (Print)

\author{
Richard J. Cebula ${ }^{a}$ \\ https://doi.org/10.37625/abr.24.2.133-146
}

\begin{abstract}
Effectively no scholarly research has been published in peer-reviewed journals on the potential migration impacts of environments that are more conducive to entrepreneurship. Similarly, the potential migration impact of personal freedom also is essentially ignored in the literature. This study seeks to add to the literature by investigating the impacts of both entrepreneurial activity and personal freedom on state in-migration patterns. Using a panel dataset for the post-Great Recession period 2010-2017, the empirical analysis reveals that all three of the Kauffman indices of entrepreneurial activity are found to exercise a positive and statistically significant impact on both net in-migration and gross in-migration. In addition, the index of overall personal freedom is found to exercise a positive and statistically significant impact on both of these in-migration measures. Thus, it appears that there may be good reason for future migration studies to take such variables into account when seeking to explain, understand, and predict migration patterns in the U.S.
\end{abstract}

\title{
KEYWORDS
}

Entrepreneurial Activity, Indices of Entrepreneurship, Personal Freedom Index, Net In-Migration, Gross InMigration

\section{INTRODUCTION TO THE STUDY}

Over the course of the last half century, numerous scholarly theoretical and empirical studies have sought to identify and quantify both economic and quality-of-life considerations as well as public policies that influence patterns of net in-migration, gross in-migration, and gross out-migration. These studies can in found in scholarly journals representing a variety of disciplines, including labor economics, environmental economics, economics, demography and population studies, political science, public choice, history, sociology, and statistics. These studies embody a variety of contexts, e.g., metropolitan, rural-urban, state-level, and so forth, and adopt a variety of econometrics techniques (Gallaway, 1969; Bowles, 1970; Gatons and Cebula, 1972; Sommers and Suits, 1973; Cebula, 1974; Falaris, 1979; Clark and Hunter, 1992; Chi and Voss, 2005; Cebula and Alexander, 2006; Francis, 2007; Martin, 2009; Gius, 2011; Plantinga, et al., 2013; Mitze and Schmidt, 2015; Johnson et al., 2017; Molloy et al., 2017; Min and Hong, 2021).

Overall, it is found that people prefer to move to environments that offer some combination of greater income and/or income growth prospects, lower housing prices or lower cost-of-living levels, and more appealing quality-of-life (including weather) conditions (Cebula and Vedder, 1973; Cebula, 1974; Justman et al, 1988; Conway and Houtenville, 2001; Chi and Voss, 2005; Francis, 2007; Gius, 2011; Young et al., 2016). Moreover, as the scholarly migration literature has developed over time, the impacts of economic freedoms on not only on income and entrepreneurship (Sobel, et al. 2007; Clark and Lawson, 2008; Hall and Lawson, 2014; Gohmann et al., 2008; Compton et al., 2011; Hall et al., 2016;

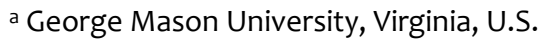

Corresponding Author:

Cebula (rcebula@gmu.edu) or (dr.richardcebula@gmail.com) 
Hall et al., 2018)) but also upon migration patterns have received growing attention (Mulholland and Hernández-Julián, 2013; Cebula, 2014, Young, et al., 2016; Shumway, 2017), with higher levels of economic freedom of one form or another, e.g., labor freedom, typically being found appealing to migrants.

By contrast, the literature to date has largely neglected/ignored the potential migration-pattern impacts of higher levels of entrepreneurial activity on the one hand and greater personal freedom on the other hand. Accordingly, this study seeks to add to the literature by empirically investigating whether recent net and gross in-migration patterns in the U.S. have been an increasing function of (a) entrepreneurial activity, i.e., environments more favorable for the development of entrepreneurship and (b) overall personal freedom. More specifically, this study seeks to investigate the impacts on net and gross in-migration resulting from higher levels of the Kauffman indices of entrepreneurial activity (Kauffman, 2017) and higher levels of personal freedom (Ruger and Sorens, 2009; Cato Institute, 2018). The indices of entrepreneurship as well as the index of overall personal freedom are treated as institutional economic dimensions of each state. By examining the pattern of in-migration for the time period 2010-2017 using a state-level panel dataset, this analysis provides a study of migration behavior that effectively encompasses most of the post-Great Recession period to date.

After developing the background and migration model in the second and third sections of this study, respectively, estimation results are provided in the subsequent section. In addition to three different measures of entrepreneurial activity and personal freedom, a number of "control variables" are integrated into the analysis. The latter include a measure of expected median income, an overall cost-of-living index to reflect commodity prices, and certain quality-of-life considerations, in order to make the modeling parallel to the conventional migration literature. Focusing on in-migration, both net and gross, is based on the idea that such migration patterns provide useful information for policymakers, who must address infra-structure and a variety of other considerations resulting from net population growth, such as police and fire protection, public health, and public education. Conclusions based upon the estimation findings are provided in final section of the study, along with suggestions for future research.

\section{BACKGROUND: ENTREPRENEURIAL ACTIVITY AND PERSONAL FREEDOM}

Entrepreneurial activity, as a measure of the degree to which the environment is conducive to entrepreneurship, is integrated into the basic model using the three Kauffman Indices of Entrepreneurial Activity (2017). The first of these indices is the "Startup Activity Report," which provides a broad measure of business startup activity in a state (Kauffman, 2017, p. 4). It is an equally weighted index of three normalized measures of startup activity, namely: (1) the "Rate of New Entrepreneurs" in the state, calculated as the percentage of adults becoming entrepreneurs in a given month; (2) the "Opportunity Share of New Entrepreneurs," calculated as the percentage of new entrepreneurs in the state driven primarily by "opportunity" as opposed to "necessity;" and (3) the "Startup Density" in the state, measured as the number of new employer businesses normalized by total business population in the state. The variable SARjt is the value of the startup index for state $j$ in year $t$.

The second of the Kauffman indices (2017, p. 4) is the "Main Street Index." In any given state, this index is an equally weighted index of three normalized measures of the extent of entrepreneurial activity: (1) the number of established small businesses in the state (the "Rate of Business Owners"); (2) the percentage survival rate of businesses in the state (the "Survival Rate"); and (3) the number of private businesses in the state older than five years with fewer than 50 employees (the "Established Small Business Density"). The variable MSljt indicates the value of the main street index in state $j$ during year $t$. 
The third Kauffman index (2017, p. 4), labelled here as the "Growth Index," measures entrepreneurship growth in a state. It is an equally weighted index of: (1) the average growth of a cohort of new startups in the state in their first five years in the state (the "Rate of Startup Growth"); (2) the number of small businesses that grew to employ at least 50 people by their tenth year of operation, expressed as a percent of all businesses ten years of age or younger (the "Share of Scaleups"); and (3) the number of fast-growing firms in the state with at least $\$ 2$ million in annual revenue, normalized by business population (the "High-Growth Company Density"). The variable GRljt represents the value of this growth index for state $j$ in year $t$.

The higher the value of any of the Kauffman indices in a state, the greater the degree of entrepreneurial activity in the state. In turn, the greater the entrepreneurial activity in any given state, at for least some would-be/potential migrants, the greater the DPV (expected net discounted present value) associated with either migrating to or remaining a resident of that state. Thus, it is hypothesized here that both gross and net state-level in-migration is an increasing function of each of these Kauffman indices because higher such values imply environments (states, in this case) that are more supportive of and receptive to entrepreneurship, ceteris paribus.

In addition to overall economic freedom, there are several well-known disaggregated indices of economic freedom, each with its own sub-indices. The principal indices are labelled as tax freedom, government spending freedom, and labor market freedom. In turn, each of these sub-indices has its own sub-indices (Stansel, 2013; Stansel, Torra, and McMahon, 2014, 2016, 2017, 2018). There are other well-known and respected economic freedom indices as well, e.g., Miller et al (2021) are listed as authors of the Heritage Foundation Index, which identifies 12 freedoms, including financial freedom, trade freedom, and property rights freedom. The freedom indices in Gwartney et al. (2013; 2016) are also very noteworthy. Personal freedom indices are far less common. This study adopts the pertinent data developed by Ruger and Sorens (2009).

Ruger and Sorens (2009) distinguish themselves from the indices of economic freedom in their measurement of personal freedom. They treat the idea of freedom in a manner that in principle is compatible with previous studies insofar as they define individual freedom in terms of "... the ability to dispose of one's own life, liberty, and justly acquired property however one sees fit, so long as one does not coercively infringe on another's ability to do the same" (Ruger and Sorens, 2009, p. 1). Starting with this premise definition of freedom, they measure the extent to which paternalistic policies infringe upon the personal freedoms of individuals in a state. Factors they utilize in this measure include state-level regulations on alcohol, home schooling, firearms, campaign finance, gambling, automobiles, gaming, incarceration prospects, and other personal regulations. For a full listing of all the data included in this measure, we refer the interested reader to the detailed Data Appendix contained in Ruger and Sorens (2009).

Ruger and Sorens (2009) argue that they improve on previous freedom measures in several ways, two of which arguably are related to our interest in better explaining domestic migration patterns during the post-Great Recession period. First, they measure important personal and social freedoms such as the rights of free and responsible individuals to educate their children as they see fit or for individuals to engage in same-sex partnerships. Second, they include more variables reflecting the diversity of personal freedom across the 50 states than do other studies. For these two reasons, and others, Ruger and Sorens (2009, p. 6) claim that their index of personal freedom "... not only provides a broader framework for understanding the state of freedom in the American states, but also more carefully measures..." its components. Consequently, we adopt the Ruger and Sorens (2009) overall personal freedom index as the personal freedom measure in the present study of determinants of U.S. internal migration. It is hypothesized in this study that, ceteris paribus, the higher the value of the personal freedom index in a state, the greater the attractiveness of that state to migrants. Personal freedom can be considered a distinct component of the quality-of-life dimension of each of the states. 


\section{THE FRAMEWORK FOR IN-MIGRATION}

Net population growth at the regional level of a nation can derive from a variety of significant sources aside from the net impacts of birth rates versus death rates, including net domestic in-migration or domestic gross-in-migration. Indeed, the latter two migration measures historically have played an extremely important role in the geographic pattern of economic growth across the U.S. (Vedder, 1976). The migration model is developed in this section of the study. We direct attention to both gross in-migration and net in-migration, although arguably patterns of net in-migration as opposed to gross in-migration may have the virtue of providing potentially greater insights into net population growth and the potential net impacts thereof upon the demand for public infrastructure and public services levels as well as the tax base (Sommers and Suits, 1973; Renas, 1978, 1983; Jennissen, 2003; Cebula, 2014; Foley and Dajci, 2015; Eliasson et al., 2015).

As is common in the migration literature, we treat the consumer-voter as viewing the migration decision as an investment decision. In principle, this procedure follows the ground-breaking theoretical and empirical work by Bowles (1970). It is noteworthy, however, that migration studies involving specific sub-groups of the total population such as only the elderly (typically, age 65 and older) do not typically adopt the migration-as-investment perspective (Gale and Heath, 2000; Conway and Houtenville, 2001) because the labor force participation rate among this cohort is far below that of the population as a whole (Council of Economic Advisors, 2020, Table B-11). Migration may instead reflect human behavior that regards the migration decision as a de facto consumer good. The decision to migrate from one location (i) to another location ( $j$ ), therefore, requires that the discounted net present value of the representative consumer-voter's expected net benefits of moving from the present location to the other location not only be positive (a "first-order" condition) but also that it reflect the maximum value that could be expected from moving from the consumer-voter's current location to any other considerable alternative feasible destination (a "second order" condition). Thus, migration will flow from area $i$ to area $j$ only if the following conditions both hold:

$$
D P V i j>0 ; \text { and } D P V i j=M A X \text { for } j, \text { where } j=1,2, \ldots, z
$$

with DPVij being the net discounted present value associated by the representative migrant or wouldbe migrant with movement from area $i$ to area $j$ and with $z$ representing all of the alternative plausible destinations for the consumer-voter within the U.S. Clearly, if the DPVij = o, residents of area will not migrate from area $i$ to area $j$, whereas if $\mathrm{DPVij}<0$, residents of area $j$ are inclined to move to area $i$, subject to the condition:

$$
\text { DPVji }=\text { MAX for } i \text {, where } i=1,2, \ldots, z \neq j
$$

In the empirical estimations, to measure the net and gross state in-migration rates into state $j$ in year $t$, NETMIGRATEjt and GRMIGRATEjt, respectively, both the net and gross numbers of in-migrants to state $j$ during year $t$ are first divided by the year $t$ total population in state $j$, with the then resulting decimals being converted into percentage form.

Under those migration-decision circumstances involving the investment perspective, typical wouldbe migrant evaluates the DPV associated with each possible destination state $(j)$ in year $t$, there are a number of expected gross benefits (EGBjt) and expected gross costs (EGCjt) that are identified by her in the migration decision calculus. Thus, the probability that the representative consumer-voter will move to area $j$ in year $t$ (PROBjt) is given by:

$$
\text { PROBjt }=f(E G B j t, E G C j t)
$$


where it is hypothesized that

$$
f_{E G B j t}>0, f_{E G C j t}<0
$$

Within this context, we investigate empirically the two hypotheses outlined in the preceding section of this study, with the understanding that the aggregate net in-migration to state $j$ in year $t$, NETMIGRATEjt, or the aggregate gross in-migration to $j$ in year $t$, GRMIGRATEjt reflects the value of PROBjt across the aggregate population, so that the following holds:

$$
\text { NETMIGRATEjt }=f(E G B j t, \text { EGCjt }) \text { and GRMIGRATEjt }=k(E G B j t, \text { EGCjt })
$$

such that:

$$
f_{E G B j t}>0, f_{E G C j t}<0 ; \text { and } k_{E G B j t}>0, k_{E G C j t}<0
$$

Pursuant to the discussion provided in the second section of this study, the principal variables of interest here are those reflecting: (1) a favorable environment for entrepreneurship (entrepreneurial activity), which is represented in this project by three indices, namely, SARjt, MSljt, and GRljt (Kauffman, 2017); and (2) personal freedom, as represented by the index in each state (PERSFREEjt) of personal freedom (Ruger and Sorens, 2009; Cato Institute, 2018). As hypothesized above, the greater the value of each one of these entrepreneurship activity indices in period/year $t$, the greater the expected benefits of moving from area $i$ to area $j$ in year $t$, ceteris paribus. Furthermore, as also hypothesized above, the greater the overall level of personal freedom in area $j$ in year $t$, the greater the expected gross benefit of moving to area $j$ in year $t$, ceteris paribus. Accordingly, it follows that:

$$
\text { EGBjt }=g(\text { SARjt, MSljt , GRljt, PERSFREEjt) }
$$

such that:

$$
\mathrm{g}_{S A R j t}>0, \mathrm{~g}_{M S l i j}>0, \mathrm{~g}_{G R l i t}>0, \mathrm{~g}_{\text {PERSFREEjt }}>0
$$

It is emphasized in this study and summarized in (4) and in (5) above, that the subjects of primary interest in this study, namely, (a) entrepreneurial activity measures and (b) overall personal freedom, both fall under the rubric of what is categorized here as being "institutional economic or personal factors/conditions." This characterization derives from the fact that the values of these variables are largely determined by political and economic institutions and circumstances found in each of the states. Aside from these four heretofore largely neglected variables, this analysis follows other prior migration studies and adopts a number of control variables, variables that fall into two very broadly defined categories of state-level conditions: purely economic conditions/factors and quality-of-life factors.

The first of the purely economic variables is the expected median household income in state $j$ in year $t$, EXPMEDHHINCjt. This variable is computed as the current level of median household income in state $j$ in year $t$, MEDHHINCjt, multiplied by the current employment rate in state $j$ in year $t$, (1.0UNEMPjt), where UNEMPjt is expressed as a decimal rather than as a percentage. Thus, as the expected income variable in the model, we have the following specification:

$$
\text { EXPMEDHHINCjt }=(1-\text { UNEMPjt }) \times \text { MEDHHINCjt }
$$


This formulation is similar to the conventional way of measuring income opportunities except that it formally integrates a measure of the probability of employment per se into the decision calculus. Thus, it allows for the possibility that the variable representing expected income potential reflects not only prevailing income levels and opportunities but also sobers the assessment thereof with considerations of the likelihood of securing the employment reflected by those income levels. Other things held the same, following the conventional wisdom, states having higher expected income levels should be more attractive to migrants because, with a higher income, people have higher living standards.

The second specified measure of purely economic prospects in state $j$ in year $t$ for would-be migrants is the COSTOFLIVjt, which is an index measuring the overall cost of living in state $j$ for the average four-person family in year $t$. This variable is expressed as an index, with the mean of this variable being approximately 100.00 . The expected impact of a higher cost of living on net state inmigration is negative. This is because, a higher overall cost of living would reduce a family unit's real purchasing power and hence its living standard and well-being, ceteris paribus.

As for the other control variables, following a number of previous studies (Cebula and Vedder, 1973; Cebula, 1974; Gallaway and Cebula, 1973; Renas, 1978; 1983; Justman, Levy, and Gabriel, 1988; Clark and Hunter, 1992; Conway and Houtenville, 2001; Chi and Voss, 2005; Francis, 2007; Gius, 2011; Young et al., 2016), we seek to reflect quality-of-life conditions in state $j$ in year $t$. Although this is not the central focus of this study, it is well established in the literature that such factors often play pivotal roles in migration decisions. Aside from the personal freedom dimension of the quality of life as considered above, two commonly considered quality-of-life control variables are included in the model, namely, the following: the variable AVJANTEMPjt, the average daily temperature in January in state $j$ in year $t$; and the variable POPDENSjt, the population density in state $j$ in year $t$, expressed in terms of persons per square mile. It is commonplace in migration studies of the U.S. to find empirical support for the hypothesis that, on average, migrants prefer residence in warmer climates (Gallaway and Cebula, 1973; Renas, 1978, 1983; Clark and Hunter, 1992; Conway and Houtenville, 2001; Gale and Heath, 2000; Cebula and Alexander, 2006; Young et al., 2016). In the present study, therefore, it is hypothesized that statelevel in-migration is expected to be an increasing function of AVJANTEMPjt, ceteris paribus. It is also hypothesized that greater population density can exercise an impact on migration patterns. On the one hand, a higher level of population density implies potentially greater access to medical care, dining, grocery stores, entertainment, and other amenities, and hence acts as an inducement for migrants, ceteris paribus. On the other hand, greater population density can, at some point imply greater congestion and perhaps higher levels of air and noise pollution, so that migrants would arguably prefer residence in states with a lower population density, ceteris paribus. Hence, the net impact of this variable on migration arguably is a priori unknown.

Once the variables of central interest here are combined with the control variables described above, the synthesized migration model can be described in terms of the expected gross benefits and expected gross costs of moving from area $i$ to area $j$, as follows:

$$
\text { EGBjt }=g(\text { SARjt, MSljt }, \text { GRljt, PERSFREEjt, EXPMEDHHINCjt, AVJANTEMPjt })
$$

such that:

$$
\mathrm{g}_{S A R j t}>0, \mathrm{~g}_{M S l i j}>0, \mathrm{~g}_{G R l j t}>0, \mathrm{~g}_{\text {PERSFREEjt }}>0, \mathrm{~g}_{\text {EXPMEDHHINCjt }}>0, \mathrm{~g}_{\text {AVJANTEMPjt }}>0
$$

and

$$
\text { EGCjt }=h(\text { COSTOFLIVjt, POPDENSjt })
$$


such that:

$$
h_{\text {COSTOFLIVjt }}>0, h_{\text {POPDENSjt }}>\leq 0
$$

Predicated upon the above, it follows that the synthesized model of the net in-migration rate to state $j$ in year $t$ should be expressed as the following:

$$
\begin{aligned}
& \text { NETMIGRATEjt = f(SARjt, MSljt , GRIjt, PERSFREEjt, EXPMEDHHINCjt, AVJANTEMPjt, } \\
& \text { COSTOFLIVjt, POPDENSjt) }
\end{aligned}
$$

where we expect that:

$$
f_{\text {SARjt }}>0, f_{\text {MSljt }}>0, f_{\text {GRlit }}>0, f_{\text {PERSFREEjt }}>0, f_{\text {EXPMEDHHINCjt }}>0, f_{\text {AVJANTEMPjt }}>0, f_{\text {COSTOFLIVjt }}<0, f_{\text {POPDENSjt }}
$$
$>\leq 0$

Similarly, the synthesized model for the gross in-migration rate, GRMIGRATEjt, is expressed as:

$$
\begin{aligned}
& \text { GROSSMIGRATEjt }=b(\text { SARjt, MSljt , GRIjt, PERSFREEjt, EXPMEDHHINCjt, AVJANTEMPjt, } \\
& \text { COSTOFLIVjt, POPDENSjt) }
\end{aligned}
$$

where it is expected that:

$$
\begin{aligned}
& b_{\text {SARjt }}>0, b_{\text {MSlit }}>0, b_{\text {GRlit }}>0, b_{\text {PERSFREEjt }}>0, b_{\text {EXPMEDHHINCjt }}>0, b_{\text {AVJANTEMPjt }}>0, b_{\text {COSTOFLIVjt }}<0, \\
& \text { bPOPDENSjt }>\leq 0
\end{aligned}
$$

\begin{tabular}{|c|c|}
\hline Variable & Data Sources \\
\hline NETMIGRATEjt and GROSSMIGRATjt & $\begin{array}{l}\text { U.S. Census Bureau. (2010, 2012, 2014, 2015, 2016A, } \\
\text { 2016B, 2017) }\end{array}$ \\
\hline MEDHHINCjt, PCINCjt, PCTHSjt, and PCTBACHjt & $\begin{array}{l}\text { U.S. Census Bureau }(2010,2012,2014,2015,2017) \text {; } \\
\text { United Health Foundation (2017) }\end{array}$ \\
\hline UNRATEjt & $\begin{array}{l}\text { U.S. Census Bureau (2010, 2011, 2012, 2014, 2015, } \\
\text { 2017) }\end{array}$ \\
\hline COSTOFLIVjt & $\begin{array}{l}\text { ACCRA (2009); Council for Community and } \\
\text { Economic Research (2016) }\end{array}$ \\
\hline PERFREEjt & Ruger and Sorens (2009); Cato Institute (2018) \\
\hline SARjt, MSljt, and GRljt & Kauffman (2017) \\
\hline POPDENSjt and AVJANTEMPjt & $\begin{array}{l}\text { U.S. Census Bureau }(2010,2012,2014,2015,2016 B \text {, } \\
\text { 2017) }\end{array}$ \\
\hline
\end{tabular}

The data sources for each of the variables described above, along with the instrumental variables described below, are provided in Table 1. In addition, the means and standard deviations, along with maximum and minimum values, for each of these variables are provided in Table 2 . The study deals with annual data for all 50 states and a balanced panel dataset involving the period 2010-2017.

Table 1. Variables and Data Sources 
Table 2. Descriptive Statistics

\begin{tabular}{cllll}
\hline Variable & \multicolumn{1}{c}{ Mean } & \multicolumn{1}{c}{$\begin{array}{l}\text { Standard } \\
\text { Deviation }\end{array}$} & Maximum & \multicolumn{1}{c}{ Minimum } \\
\hline NETMIGRATEjt & 0.125 & 0.849 & 1.96 & -8.96 \\
GROSSMIRATEjt & 2.839 & 0.965 & 6.139 & 1.171 \\
EXPMEDHHINCjt & 49,220 & 7,140 & 67,669 & 32,654 \\
COSTOFLIVjt & 101.92 & 16.24 & 172.62 & 83.71 \\
PERSFREEjt & 0.0063 & 0.08867 & 0.257 & -0.566 \\
AVJANTEMPjt & 30.809 & 12.66 & 74.1 & -12.8 \\
SARjt & -0.612 & 1.468 & 3.87 & -3.83 \\
MSIjt & 0.198 & 1.364 & 3.97 & -4.063 \\
GRIjt & 0.145 & 2.015 & 6.93 & -4.50 \\
POPDENSjt & 176.71 & 223.52 & $1,088.8$ & 1.161 \\
MEDHHINCjt & 52,828 & 6,990 & 72,358 & 34,735 \\
UNRATEjt & 6.58 & 2.09 & 13.53 & 2.675 \\
PCINCjt & 43,044 & 7,461 & 69,311 & 29,801 \\
Log(PCINCjt) & 10.65 & 0.166 & 11.13 & 10.30 \\
PCTHSjt & 87.60 & 3.27 & 92.80 & 79.60 \\
PCTBACHjt & 28.12 & 4.86 & 40.50 & 17.10 \\
N=350 & & & & \\
\hline
\end{tabular}

\section{ESTIMATION RESULTS}

The fundamental focus in this study is on the impact of the three indices of entrepreneurial activity and on the impact of the index of overall personal freedom, on state-level net and gross in-migration in the U.S. over the 2010-2017 post-Great Recession period. From equation (11) and the associated (12) above and from equation (13) and the associated (14) above, the models to be estimated by Panel 2SLS are expressed in equations (15) and (17):

$$
\begin{aligned}
& \text { NETMIGRATEjt }=a_{0}+a_{1} \text { SARjt- } 1+a_{2} \text { MSljt- } 1+a_{3} \text { GRljt- } 1+a_{4} \text { PERSFREEjt- } 1+a_{5} \text { EXPMEDHHINCjt } \\
& +a_{6} \text { AVJANTEMPjt- } 1+a_{7} \text { COSTOFLIVjt }+a_{8} \text { POPDENSjt- } 1+\varepsilon j t
\end{aligned}
$$

where $a_{0}=$ constant term and $\varepsilon j t=$ the stochastic error term. Based upon the preceding discussion, the following coefficient signs are hypothesized:

$$
\begin{aligned}
& a_{1}>0, a_{2}>0, a_{3}>0, a_{4}>0, a_{5}>0, a_{6}>0, a_{7}<0, a_{8}>\leq 0 \\
& \text { GROSSMIGRATEjt }=b_{0}+b_{1} \text { SARjt-1 }+b_{2} \text { MSljt-1 }+b_{3} \text { GRljt-1 }+b_{4} \text { PERSFREEjt-1 + } b_{5} \text { EXPMEDHHINCjt } \\
& +b_{6} \text { AVJANTEMPjt-1 }+b_{7} \text { COSTOFLIVjt }+b_{8} \text { POPDENSjt- } 1+\varepsilon j t
\end{aligned}
$$

where it is expected that:

$$
b_{1}>0, b_{2}>0, b_{3}>0, b_{4}>0, b_{5}>0, b_{6}>0, b_{7}<0, b_{8}>\leq 0
$$

The primary interest of this study is reflected by the estimated coefficients for $a_{1}, a_{2}, a_{3}$, and $a_{4}$ in equation (15) for net in-migration on the one hand and their counterparts in equation (17) for gross inmigration. In these specifications, although the non-purely economic variables are all lagged, both 
purely economic variables, EXPMEDHHINCjt and COSTOFLIVjt, are both unlagged. Arguably, migrants would tend to have a more current/updated working knowledge of the values of these two variables, whereas their knowledge of the remaining variables in the model would likely be less current or simply less available.

In any event, given that the dependent variable in equation (15) and in equation (17) is in each case contemporaneous with both EXPMEDHHINCjt and COSTOFLIVjt, the possibility of simultaneity bias arises. To address this issue, the models are estimated using Panel 2SLS (panel two-stage least squares). Accordingly, appropriate instrumental variables must be identified for these two purely economic factors. The instruments chosen were the two-year lags of both the natural log of per capita personal income, $\log (P C I N C j t-2)$, and the square of the total state population (POPSQjt-2), as suggested in Isard (1956), for the explanatory variable COSTOFLIVjt on the one hand and the two-years lags of both the percentages of the adult population age 25 years of age and older with a high school diploma (PCTHSjt-2) and the percentage thereof with a four-year bachelor degree (PCTBACHjt-2), as implied in Gallaway (1969), for the variable EXPMEDHHINCjt. Each of these instruments is highly correlated with the explanatory variable with which it is associated, whereas each of these instruments is also uncorrelated with the error term.

The Panel 2SLS estimate of equation (15) is summarized in Table 3, which exhibits robust standard errors. In this Table, all eight estimated coefficients exhibit the expected signs; furthermore, seven of these coefficients are statistically significant at the $1 \%$ level and one is statistically significant at the $5 \%$ level. The F-statistic is significant at the $1 \%$ level, thus providing strong evidence of the overall significance of the model specification, whereas the J-statistic is significant at the $1 \%$ level, attesting favorably to the exogeneity of the instruments that were adopted, i.e., attesting to the presence of appropriate instruments. For the interested reader, it is further observed that the first-stage F-statistic clearly establishes the instruments as not being weak, per Stock et al (2002, esp. p. 522).

Table 3. Panel 2SLS Estimation Results for Net In-Migration

\begin{tabular}{cllll}
\hline Explanatory Variable & \multicolumn{1}{c}{ Coefficient } & \multicolumn{1}{c}{ Std. Error } & t-statistic & Prob. \\
\hline EXPMEDHHINCjt & $0.00205^{* *}$ & 0.00037 & 5.47 & 0.0000 \\
COSTOFLIVjt & $-0.032^{* * *}$ & 0.00259 & -12.32 & 0.0000 \\
PERSFREEjt-1 & $0.0208 * * *$ & 0.00389 & 5.33 & 0.0000 \\
AVJANTEMPjt-1 & $0.0296 * * *$ & 0.00299 & 9.89 & 0.0000 \\
SARjt-1 & $0.0437^{* *}$ & 0.02169 & 2.02 & 0.0445 \\
MSljt-1 & $0.168 * * *$ & 0.03055 & 5.50 & 0.0000 \\
GRljt-1 & $0.0249 * * *$ & 0.00902 & 2.76 & 0.0061 \\
POPDENSjt-1 & $0.0007^{* * *}$ & 0.00014 & 4.58 & 0.0000 \\
Constant & 1.31 & & & 0.0000 \\
F-statistic & $24.68 * * *$ & & & 0.0006 \\
J-statistic & $171.4 * * *$ & & & \\
N=350 & & & & \\
\hline
\end{tabular}

***Statistically significant at the $1 \%$ level; **statistically significant at the $5 \%$ level.

Focusing first on the control variables, the net in-migration rate is shown to be a decreasing function of the cost-of-living index, whereas it is shown to be an increasing function of a higher expected median family income, population density, and the prospect of warmer January temperatures, i.e., warmer climate. These control variable findings are compatible with the vast majority of empirical migration studies (e.g., Cebula and Vedder, 1973; Renas, 1978, 1983; Conway and Houtenville, 2001; Chi and Voss, 2005; Cebula and Alexander, 2006; Francis, 2007; Gale and Heath, 2000; Gius, 2011; Plantinga et al., 2013). 
As for the primary variables of interest in this study, the estimation shown in Table 3 reveals first that the net in-migration rate at the state level has been an increasing function of each of the three of the entrepreneurial activity variables, SARjt (at the $1 \%$ level), MSljt (at the 1\% level), and GRljt (at the $5 \%$ level). Therefore, as hypothesized, the higher the value of each of these entrepreneurial activity indices in a state, the greater the net in-migration rate to that state, other things held the same. Hence, it is found that increasingly entrepreneurship-friendly environments lead to an increased net inmigration rate. Interestingly, although within the context of a quite different specification, a recent study by Cebula et al. (2020) investigates the potential bi-directional relationship between an overall measure of entrepreneurship and gross migration patterns in the U.S., finding that entrepreneurship thusly measured exercises no discernible impact on gross in-migration, although greater gross inmigration seems to induce increased entrepreneurship, which appears to be compatible with the study of migration in Sweden by Eliasson et al. (2015).

Furthermore, the net in-migration rate is shown to also have been an increasing function of overall personal freedom, as hypothesized here and previously suggested by the findings in Cebula (2014). Thus, the higher the overall personal freedom index in a state, the greater the net in-migration rate to the state, other things held constant. Based upon this finding, it would appear that policies promoting personal freedom would increase net in-migration and hence both population and economic growth.

Table 4. Panel 2SLS Estimation Results for Gross In-Migration

\begin{tabular}{cllll}
\hline Explanatory Variable & \multicolumn{1}{c}{ Coefficient } & \multicolumn{1}{c}{ Std. Error } & t-statistic & Prob. \\
\hline EXPMEDHHINCjt & $0.0128^{* * *}$ & 0.00176 & 7.29 & 0.0000 \\
COSTOFLIVjt & $-0.0884^{* * *}$ & 0.01462 & -6.05 & 0.0000 \\
PERSFREEjt-1 & $0.0463^{* * *}$ & 0.00857 & 4.36 & 0.0000 \\
AVJANTEMPjt-1 & $0.0245^{* * *}$ & 0.00857 & 2.86 & 0.0044 \\
SARjt-1 & $0.437^{* * *}$ & 0.05721 & 7.65 & 0.0000 \\
MSIjt-1 & $0.2025^{* * *}$ & 0.06903 & 2.94 & 0.0036 \\
GRljt-1 & $0.1757^{* * *}$ & 0.03940 & 4.46 & 0.0000 \\
POPDENSjt-1 & $0.004^{* * *}$ & 0.00076 & 5.19 & 0.0000 \\
Constant & 0.529 & & & \\
F-statistic & $24.85^{* * *}$ & & & 0.0000 \\
J-statistic & $8.64^{* *}$ & & & 0.0489 \\
N=350 & & & & \\
\hline
\end{tabular}

***Statistically significant at the $1 \%$ level; **statistically significant at the $5 \%$ level.

Arguably, focusing on net migration can be questioned to some degree to the extent that when investigating economic behavior, it is difficult to identify an actual "net migrant" per se. With this perspective in mind, the estimation of equation (17) may potentially be of greater interest than equation (15) since in-migrants per se are clearly identifiable economic agents. Proceeding accordingly, the Panel 2SLS estimate of equation (17) is of relevance. Focusing upon this estimate in Table 4, reveals a pattern of factors arguably impacting gross in-migration that is indeed very similar to, i.e., parallels, that found in Table 3. In particular, all eight of the estimated coefficients shown in Table 4 are found to be statistically significant at the $1 \%$ level with the expected signs. Consequently, with respect to the control variables, the gross in-migration rate is an increasing of population density, warmer temperatures, and expected income, while being a decreasing function of the cost of living. Of greater interest from the focus of this study, the gross in-migration rate is an increasing function of all three measures of entrepreneurial activity as well as personal freedom. Finally, it is noteworthy that the Fstatistic is significant at the $1 \%$ level, which suggests strong evidence of the overall significance of the 
model specification, whereas the J-statistic is significant at the $5 \%$ level, attesting favorably to the exogeneity of the instruments that were adopted, i.e., attests to the appropriateness of the instruments. ${ }^{1}$

\section{CONCLUSION}

This study has empirically investigated the impact of entrepreneurial activity as well as the impact of overall personal freedom, two factors largely ignored in the scholarly migration literature, on both the domestic net in-migration rate and gross in-migration rate at the state level within the U.S. during the Post Great Recession period (which includes most of the post-Great Recession period to date, 20102017). More specifically, using an overall average index of personal freedom and the Kauffman indices of entrepreneurial activity, this study investigates whether state-level domestic in-migration has in fact been positively impacted by higher levels of entrepreneurial activity and personal freedom.

The results of the empirical estimations are provided in Tables 3 and 4. From the viewpoint of the objective of this study, the most germane of these statistical findings are that both net and gross inmigration have been positively impacted by higher levels of entrepreneurial activity as well as by higher levels of personal freedom. Indeed, there is compelling evidence strongly suggesting that states having higher levels of entrepreneurial activity face the prospect of greater net and gross inmigration rates and the concomitant additional population and economic growth that would accompany same, ceteris paribus. Similarly, states characterized by higher levels of overall personal freedom can be expected to experience greater in-migration rates and hence, over time, higher population growth and, logically, a higher rate of economic growth as well, ceteris paribus. Interestingly, adding the gross in-migration rate with a lag of 5 years to the right-hand-side of the estimation, as arguably implied to be potentially appropriate in the studies by Deller et al (2019) and Cebula et al (2020), exercises very little impact on the overall results and does not alter any of its basic conclusions.

Naturally, further analysis is needed to establish definitive conclusions on the issues emphasized in this study. For example, there may be great value in estimating the model after adopting more or simply different control variables or, when feasible, to including more recent data, although the Kauffman series was computed differently after the year 2017. In any event, it is also noteworthy that a variety of alternative specifications of this framework yielded the very same conclusions as implied by the results in Tables 3 and 4 .

Clearly, there may be reason to believe that policies expressly supportive of entrepreneurial activity may reap benefits in terms of attracting migrants and stimulating population growth and job growth. Policymakers might consider introducing a paradigm to promote entrepreneurial endeavors. It might, for example, be helpful to make it less onerous procedurally to start a business ("less paperwork" involved and shorter time periods to obtain what remains necessary paperwork). It also might be useful to cut the costs of starting a business, e.g., lower priced business licenses and shorter time periods required to secure a business license. Furthermore, fewer restrictions on human behavior that enhance personal and social freedoms such as the rights of free and responsible individuals to educate their children as they see fit or the rights of individuals to engage in same-sex partnerships may prove to yield economic benefits. Given the potential policy implications of these findings, the issues presented here probably warrant further examination (Deller et al, 2019; Eliasson et al, 2015; Cebula et al, 2020).

\footnotetext{
${ }^{1}$ As was the case the net in-migration specification, the first-stage F-statistic clearly establishes the instruments as strong i.e., as not being weak instruments (Stock et al, 2002, esp. p. 522).
} 


\section{REFERENCES}

ACCRA., Cost of Living Index, (2009), Fairfax, VA: George Mason University, Council for Community and Economic Research.

Bowles, S., Migration as Investment: Empirical Tests of the Human Investment Approach to Geography Mobility, Review of Economics and Statistics, (1970), vol. 52, pp. 356-362.

Cato Institute, Freedom in the 50 States, 2017-2018, (2018), at: https://www.freedominthe50states.org/about

Cebula, R.J., Interstate Migration and the Tiebout Hypothesis: An Analysis according to Race, Sex, and Age, Journal of the American Statistical Association, (1974), vol. 69, pp. 876-879.

Cebula, R.J., The Impact of Economic Freedom and Personal Freedom on Net In-Migration in the U.S.: A State-Level Empirical Analysis, 2000-2010, Journal of Labor Research, (2014), vol. 35, pp. 88103.

Cebula, R.J., and Alexander, G., Determinants of Net Interstate Migration, 2000-2004, Journal of Regional Analysis and Policy, (2006), vol. 27, pp. 116-123.

Cebula, R.J., and Vedder, R.K., A Note on Migration, Economic Opportunity, and the Quality of Life, Journal of Regional Science, (1973), vol. 13, pp. 205-211.

Cebula, R.J., Davis, Malissa L., Koch, J.V., and Saunoris, J.W., The Relationship between Entrepreneurial Activity and Domestic Gross State In-migration Patterns in the U.S., Applied Economics, (2020), vol. 54, pp. 4542-4556.

Chi, G., and Voss, P.R., Migration Decision-making: A Hierarchical Regression Approach, Journal of Regional Analysis and Policy, (2005), vol. 35, pp. 11-22.

Clark, D.E, and Hunter, W.J., The Impact of Economic Opportunity, Amenities, and Fiscal Factors in AgeSpecific Migration Rates, Journal of Regional Science, (1992), vol. 32, pp. 349-365.

Clark, J.R., and Lawson, R.A., The Impact of Economic Growth, Tax Policy and Economic Freedom on Income Inequality, The Journal of Private Enterprise, (2008), vol. 24, pp. 23-32.

Compton, R.A., Giedeman, D.C, and Hoover, G.A, Panel Evidence on Economic Freedom and Growth in the United States, European Journal of Political Economy, (2011), vol. 27, pp. 423-435.

Conway, K.S., and Houtenville, A.J., Elderly Migration and State Fiscal Policy: Evidence from the 1990 Census Migration Flows, National Tax Journal, (2001), vol. 54, pp. 103-23.

Council for Community and Economic Research, Cost of Living by State, (2016), at: www.czer.org or www.top50states.com/cost-of-living-bystate.html

Council of Economic Advisors, Economic Report of the President, 2020, (2020), Washington, D.C.: U.S. Government Printing Office.

Deller, S. Kures, M., and Conroy,T., Rural Entrepreneurship and Migration, Journal of Rural Studies, (2019), vol. 66, pp. 38-42.

Eliasson, K., Westlund, H., and Johansson, K., Determinants of Net Migration to Rural Areas, and the Impacts of Migration on Rural Labor Markets and Self-Employment in Rural Sweden, European Planning Studies, (2015), vol. 21, pp. 693-709.

Falaris, E.M., The Determinants of Internal Migration in Peru: An Economic Analysis, Economic Development and Cultural Change, (1979), vol. 27, pp. 327-342.

Foley, M. and Dajci, F., Net Migration Determinants, Journal of Regional Analysis and Policy, (2015), vol. 45, pp. 30-35.

Francis, J., Asymmetries in Regional Labor Markets, Migration, and Economic Geography, The Annals of Regional Science, (2007), vol. 41, pp. 124-144.

Gale, L.R., and Heath, W.C., Elderly Internal Migration in the U.S. Revisited, Public Finance Review, (2000), vol. 28, pp. 153-157. 
Gallaway, L.E., Age and Labor Mobility Patterns, Southern Economic Journal, (1969), vol. 36, pp. 171-180. Gallaway, L.E., and Cebula, R.J., Differentials and Indeterminacy in Wage Rate Analysis: An Empirical Note, Industrial and Labor Relations Review, (1973), vol. 26, pp. 991-995.

Gatons, P.K., and Cebula, R.J., Wage-Rate Analysis: Differentials and Indeterminacy, Industrial and Labor Relations Review, (1972), vol. 25, pp. 207-212.

Gius, M., The Effect of Income Taxes on Interstate Migration: An Analysis by Age and Race, The Annals of Regional Science, (2011), vol. 46, pp. 205-218.

Gohmann, S. F., Hobbs, B. K., and McCrickard, M., Economic Freedom and Service Industry Growth in the United States, Entrepreneurship Theory and Practice, (2008), vol. 32, pp. 855-874.

Gwartney, J., Lawson, R.A., and Hall, J., Economic Freedom of the World: 2013, (2013), Annual Report. Vancouver: Fraser Institute.

Gwartney, J., Lawson, R.A., and Hall, J., Economic Freedom of the World: 2016, Annual Report, (2016), Vancouver: Fraser Institute.

Hall, J., and Lawson, R.A., Economic Freedom of the World: An Accounting of the Literature, Contemporary Economic Policy, (2014), vol. 32, pp.1-19

Hall, L. Lacombe, D., and Shaughnessy, T., Economic Freedom and Income Levels across U.S. States: A Spatial Econometric Analysis, Contemporary Economic Policy, (2018), vol. 37, pp. 40-49.

Hall, J.C., Lacombe, D.J., and Pokharel, S.B., Freedom and Entrepreneurship: A Spatial Econometric Framework, Journal of Entrepreneurship and Public Policy, (2016), vol. 5, pp. 404-411.

Isard. W. (1956). Location and Space Economy. Cambridge, MA: M.I.T. Press.

Jennissen, R., Economic Determinants of Net International Migration in Western Europe, European Journal of Population, (2003), vol. 19, pp. 171-198.

Johnson, K.M., Curtis, K.J., and Egan-Robertson, D., Frozen in Place: Net Migration in Sub-National Areas of the United States in the Er of the Great Recession, Population Development Review, (2017), vol. 45, pp. 599-623.

Justman, M., Levy, A., and Gabriel, S., Determinants of Interstate Migration in Israel:

Expected Returns and Risks, Applied Economics, (1988), vol. 20, pp. 679-690.

Kauffman Foundation, The Kauffman Index | Kauffman.org, (2017), at: http://www.Kauffman.org/kauffman-index

Martin, P., Recession and Migration: A New Era for Labor Migration? International Migration Review, (2009), vol. 43, pp. 671-691.

Miller, T., Kim, A.B., and Roberts, J.A., 2021 Index of Economic Freedom, (2021), Washington, D.C.: The Heritage Foundation.

Mitze, T., and Schmidt, T.D., Internal Migration, Regional Labor Markets and the Role of Agglomeration Economies, Annals of Regional Science, (2015), vol. 55, pp. 61-101.

Min, S., and Hong, S., Fighting the Wrong Battle: The Effects of Immigrant Inflows on Domestic Migration of Natives Versus Settled Immigrants in the U.S.A., Annals of Regional Science, (2021), vol. 66, pp. 57-74.

Molloy, R., Smith, C.J., and Wozniak., Job Changing and the Decline in Long-Distance Migration in the United States, Demography, (2017), vol. 54, pp. 631-653.

Mulholland, S., and Hernández-Julián, R., Does Economic Freedom Lead to Selective Migration by Education? Journal of Regional Analysis and Policy, (2013), vol. 43, pp. 65-87.

Plantinga, A.J., Detang-Dessendre, C., Hunt, G.L., and Piguet, V., Housing Prices and Inter-urban Migration, Regional Science and Urban Economics, (2013), vol. 43, pp. 296-306.

Renas, S.M., The Cost of Living, Labor Market Opportunities, and the Migration Decision, Annals of Regional Science, (1978), vol. 15, pp. 95-104. 
Renas, S.M., The Cost of Living, Labor Market Opportunities, and the Migration Decision: More on Problems of Misspecification and Aggregation Bias, Annals of Regional Science, (1983), vol. 17, pp. 98-110.

Ruger, W.P., and Sorens, J., Freedom in the 50 States: An Index of Personal and Economic Freedom, (2009), Fairfax, VA: The Mercatus Center, George Mason University.

Shumway, J.M., Economic Freedom, Migration and Income Change among U.S. Metropolitan Areas, Current Urban Studies, (2017), vol. 6, pp. 1-20.

Sobel, R.S., Clark, J.R., and Lee, D.L., Freedom, Barriers to Entry, Entrepreneurship, and Economic Progress, The Review of Austrian Economics, (2007), vol. 20. pp. 221-236.

Sommers, P.M., and Suits, D.B., An Analysis of Net Interstate Migration, Southern Economic Journal, (1973), vol. 40, pp. 193-201.

Stansel, D., An Economic Freedom Index for U.S. Metropolitan Areas, Journal of Regional Analysis and Policy, (2013), vol. 43, pp. 3-20.

Stansel, D., Torra, J, and McMahon, F., Economic Freedom of North America 2014, (2014), Vancouver: Fraser Institute.

Stansel, D., Torra, J, and McMahon, F., Economic Freedom of North America 2016, (2016), Vancouver: Fraser Institute.

Stansel, D., Torra, J, and McMahon, F., Economic Freedom of North America 2017, (2017), Vancouver: Fraser Institute.

Stansel, D., Torra, J, and McMahon, F., Economic Freedom of North America 2018, (2018), Vancouver: Fraser Institute.

Stock, J.H., Wright, J.H., and Yogo, M., A Survey of weak Instruments and Weak Identification in Generalized Method of Moments, Journal of Business and Economic Statistics, (2002), vol. 20, pp. 518-529.

U.S. Census Bureau, American Community Survey Briefs, (2016B). at: www.census.gov/content/dam/Census/library/publications/2016/demo/acsbr15-02.pdf

U.S. Census Bureau, Statistical Abstract of the United States, 2010, (2010), Washington, D.C.: U.S. Government Printing Office.

U.S. Census Bureau, Statistical Abstract of the United States, 2011 (2011), Washington, D.C.: U.S. Government Printing Office.

U.S. Census Bureau, Statistical Abstract of the United States, 2012, (2012), Washington, D.C.: U.S. Government Printing Office.

U.S. Census Bureau, Current Population Survey, Annual Social and Economic Supplement, (2014), Washington, D.C.: U.S. Government Printing Office.

U.S. Census Bureau. Current Population Survey, Annual Social and Economic Supplement, (2015), Washington, D.C.: U.S. Government Printing Office.

U.S. Census Bureau, Current Population Survey, Annual Social and Economic Supplement, (2016A),Washington, D.C.: U.S. Government Printing Office.

U.S. Census Bureau, Current Population Survey, Annual Social and Economic Supplement, (2017), Washington, D.C.: U.S. Government Printing Office.

United Health Foundation, Median Household Income, (2017). at: https://www.americashealthrankings.org/explore/annual/measure/Overall_a/state/ALL

Vedder, R.K., The American Economy in Perspective, (1976), Belmont, CA, Wadsworth.

Young, C., Varner, C., Lurie, I.Z., and Prisionzano, R., Millionaire Migration and Taxation of the Elite: Evidence from Administrative Data, American Sociological Review, (2016), vol. 81, pp 421-446. 